\title{
Identifying barriers for ICT development in companies' registration office
}

\author{
Rasool Mehdian* and Gholamreza Hashemzadeh
}

${ }^{a}$ Department of Management, South Tehran Branch, Islamic Azad University, Tehran, Iran

\section{H R O N I C L E}

\section{Article history:}

Received January 20, 2014

Accepted 30 August 2014

Available online

September 152014

Barrier

Business development

Noncommercial business

registration organization \begin{abstract}
A B S T R A C T
One of the necessary issues in business development is to register it with government, which helps an organization gain an official identification. However, registering a firm with government often involves with many challenges in different countries. The recent advances in information technology have created tremendous opportunities to expedite the process of business development. This paper presents an empirical investigation to prioritize various factors influencing on information and communication technology development in noncommercial business registration office in Iran. The proposed study designs a questionnaire with eight categories and distributes it among some experts. The results of our survey indicate that Creating a sense of urgency is number one important factor followed by Appropriate planning, Form a coalition FAQ, Fixed improvements, Empowering, Creating a good perspective, New approaches to institution-building and Explanation of Vision.
\end{abstract}

(C) 2014 Growing Science Ltd. All rights reserved.

\section{Introduction}

One of the necessary issues in business development is to register it with government, which helps an organization gain an official identification. However, registering a firm with government often faces with many challenges in different countries. The recent advances in information technology have created tremendous opportunities to expedite the process of business development. Analytical hierarchy process (AHP) (Saart, 1998, 1999, 1990a, 1990b) has been recognized as the most popular techniques for ranking different factors (Badreddine \& Ben Amor, 2010; Skeat \& Roddam, 2010; Wu $\& \mathrm{Li}, 2004)$. Nagesha and Balachandra (2006) identified relevant barriers to energy efficiency and their dimensions in small scale industry clusters. Shi et al. (2008) studied barriers to the implementation of cleaner production in Chinese SMEs including government, industry and expert stakeholders' perspectives. Wijayatunga et al. (2006) investigated different strategies to overcome barriers for cleaner generation technologies in small developing power systems in a case study of Sri Lanka case study. Armacost et al. (1994) applied a concurrent engineering technique to investigate the production of an important component in industrialized housing, a manufactured exterior structural wall panel. 
Ossadnik and Lange (1999) employed the results of the evaluation to generate paired firms, which were integrated into an AHP-based decision model. Adaji et al. (2011) explored the sociotechnical barriers in the implementation of web based diabetes care plans in general practice from the perspective of implementing stakeholders. Sharma et al. (2012) used AHP for ranking various factors influencing on knowledge management implementation. Sizhen et al. (2005) presented some studies on barriers for promotion of clean technology in SMEs of China using AHP technique. Meziani (2003) used AHP method for assessing the effect of investment barriers on international capital flows using an expert-driven system. Wang and Liao (2011) provided AHP analysis on barrier influent factors of management communication. Ichihara and Uchida (2014) prioritized different barriers to implementing more CDM projects in Indonesia using AHP technique. Jafarnejad and Ajalli (2014) proposed a fuzzy AHP approach for ranking the application barriers of electronic government in Iran.

\section{The proposed study}

This paper presents an empirical investigation to prioritize various factors influencing on information and communication technology development in noncommercial business registration office. The proposed study designs a questionnaire with eight categories and distributes it among some experts. Table 1 demonstrates the results of Cronbach alpha.

\section{Table 1}

The summary of Cronbach alpha

\begin{tabular}{lc}
\hline Attribute & Cronbach alpha \\
\hline Create a sense of urgency & 0.917 \\
Creating a good perspective & 0.837 \\
Explanation of Vision & 0.706 \\
Empowering & 0.862 \\
Planning & 0.819 \\
Fixed improvements & 0.763 \\
Form a coalition FAQ & 0.895 \\
New approaches to institution-building & 0.81 \\
\hline Total questionnaire & 0.954 \\
\hline
\end{tabular}

As we can observe from the results of Table 1, all components of the survey are well above the minimum acceptable level of 0.7 and this confirms the overall questionnaire.

The proposed study uses analytical hierarchy process (AHP) to prioritize eight factors influencing ICT development in noncommercial business registration organization in Iran. Next, we present details of the implementation of AHP method.

\section{The results}

In this section, we present details of our survey on investigating different factors. In our computations, we use geometric mean to calculate the average scores given to each factor. Table 2 shows details of our survey on ranking various factors.

As we can observe from the results of Table 2, creating a sense of urgency is number one important factor followed by appropriate planning, forming a coalition FAQ, fixed improvements, empowering, creating a good perspective, new approaches to institution-building and explanation of vision. Now, we can present details of the sub-factors and ranking of each part. 
Table 2

The summary of ranking the main factors

\begin{tabular}{llc}
\hline Attribute & Score & Rank \\
\hline Creating a sense of urgency & 0.240 & 1 \\
Creating a good perspective & 0.075 & 6 \\
Explanation of Vision & 0.053 & 8 \\
Empowering & 0.094 & 5 \\
Planning & 0.202 & 2 \\
Fixed improvements & 0.157 & 4 \\
Form a coalition FAQ & 0.118 & 3 \\
New approaches to institution-building & 0.061 & 7 \\
\hline Total questionnaire & 0.954 & \\
\hline
\end{tabular}

\subsection{Creating a sense of urgency}

This factor includes two sub-factor including lack of awareness among managers and economic circumstances. The implementation of AHP on these two factors has indicated that economic conditions with an average weight of 0.778 is more important than lack of awareness among managers with average weight of 0.222 . Inconsistency ratio is also less than 0.1 , which confirms the overall survey.

\subsection{Creating a good perspective}

In our study, building a good perspective is the second factor with four factors. The implementation of AHP has indicated that insufficient attention to organizational behaviors is number one priority with average rate of 0.437 followed by mismatch among the needs of the organization with average score of 0.233 , applying systems originally developed for private sectors in governmental agencies with average score of 0.201 and lack of long-term vision with an average score of 0.129 . The consistency ratio of this item is equal to 0.03 , which confirms the questionnaire.

\subsection{Explanation of Vision}

Explanation of Vision is the third item, which is investigated in our survey and it includes two items of complexity of implementation and difficulty of cost implementation. The study indicates that complexity of implementation with average score of 0.67 is twice as important as justifying cost implementation.

\subsection{Empowering}

Empowering is the next factor in our survey with three factors including inappropriate rules and regulations, job security and lack of willingness to change. In our survey, lack of appropriate rules and regulations is the most important barrier for ICT implementation, 0.677 , followed by fear on hob security, 0.186, and lack of willingness to change with average score of 0.137 . In addition, inconsistency ratio has been calculated as $0.008<0.1$.

\subsection{Planning}

Having a good planning is the next factor associated with the proposed study of this paper with four sub-factors including weak planning, insufficient suppliers, financial limitations and high expenses. In our survey, weak planning is the most important factor, 0.563, followed by high expenses, 0.192 , financial limitations, 0.141 and insufficient suppliers, 0.104 . 


\subsection{Fixed improvements}

Fixed improvements are the next factors, which contribute on ICT development and there are two sub-components including insufficient human resources, 0.75 , as well as lack of infrastructure, 0.25. The experts who were surveyed believed human resources development plays essential role for business development in this sector.

\subsection{Forming a coalition FAQ}

Forming a coalition FAQ is another important factor influencing on the business development, which includes three sub-components including lack of consensus among managers, existence of conflicts among managers and instability in execution team. In our survey, the first sub-factor is the most important factor, 0.524 , followed by the last sub-factor, 0.279 and the second item. The consistency ratio has been calculated as $0.00352<0.1$.

\subsection{New approaches to institution-building}

Finally, new approaches to institution-building is the last item in our survey with two sub-factor including inappropriate implementation and disregarding firm's objectives. In our survey, the first sub-factor is twice as important as the second one.

\section{Discussion and conclusion}

We have presented an empirical investigation to determine and prioritize important factors influencing on ICT development in noncommercial business registration organization. The proposed study has determined eight main factors each with various sub-components. Using AHP method, the study has prioritized different factors. Table 3 demonstrates the summary of various factors.

\section{Table 3}

The summary of ranking different factors

\begin{tabular}{llc}
\hline Item & Description & Score \\
\hline 1 & Lack of consensus among managers & 0.151 \\
2 & Weak planning & 0.127 \\
3 & Insufficient human resources & 0.099 \\
4 & Lack of support from top management & 0.075 \\
5 & Weak rules and regulations & 0.060 \\
6 & Lack of attention to organizational behavior & 0.047 \\
7 & Lack of awareness in management team & 0.043 \\
8 & High expenses & 0.043 \\
9 & Instability in executive team & 0.040 \\
10 & Inappropriate implementation & 0.039 \\
11 & Complexity of the system & 0.033 \\
12 & Lack of good infrastructure & 0.033 \\
13 & Financial limitations & 0.032 \\
14 & Conflict in executive team & 0.028 \\
15 & Lack of agreement with organizational needs & 0.025 \\
16 & Insufficient suppliers & 0.024 \\
17 & Implementation of what is used for governmental agencies designed for private firms & 0.022 \\
18 & Ignoring organizational objectives & 0.019 \\
19 & Difficulty in justifying expenses & 0.017 \\
20 & Endangering job security & 0.016 \\
21 & Lack of long-term vision & 0.014 \\
22 & Lack of intention to change & 0.012 \\
\hline
\end{tabular}


As we can observe from the results of Table 3, Lack of consensus among managers is the most important factor followed by weak planning, insufficient human resources, lack of support from top management and weak rules and regulations.

\section{Acknowledgement}

The authors would like to thank the anonymous referees for constructive comments on earlier version of this paper.

\section{References}

Adaji, A., Schattner, P., \& Piterman, L. (2011). Web based diabetes care planning: Sociotechnical barriers to implementation in general practice. Australian Family Physician, 40(11), 915.

Armacost, R. L., Componation, P. J., Mullens, M. A., \& Swart, W. W. (1994). An AHP framework for prioritizing customer requirements in QFD: an industrialized housing application. IIE transactions, 26(4), 72-79.

Badreddine, A., \& Ben Amor, N. (2010, May). A dynamic barriers implementation in Bayesian-based bow tie diagrams for risk analysis. InComputer Systems and Applications (AICCSA), 2010 IEEE/ACS International Conference on (pp. 1-8). IEEE.

Ichihara, J., \& Uchida, T. (2014). Prioritizing barriers to implementing more CDM projects in Indonesia: An Application of AHP. Asian Social Science,10(18), p191.

Jafarnejad, A., \& Ajalli, M. (2014). A fuzzy AHP approach for ranking the application barriers of electronic government in Iran. Social and Basic Sciences Research Review, 2(2), 67-84.

Meziani, A. S. (2003). Assessing the effect of investment barriers on international capital flows using an expert-driven system. Multinational Business Review, 11(2), 49-74.

Nagesha, N., \& Balachandra, P. (2006). Barriers to energy efficiency in small industry clusters: multi-criteria-based prioritization using the analytic hierarchy process. Energy, 31(12), 1969-1983.

Ossadnik, W., \& Lange, O. (1999). AHP-based evaluation of AHP-Software. European journal of operational research, $118(3), 578-588$.

Saaty, T. L. (1988). What is the analytic hierarchy process? (pp. 109-121). Springer Berlin Heidelberg.

Saaty, T. L. (1989). Group decision making and the AHP. In The Analytic Hierarchy Process (pp. 5967). Springer Berlin Heidelberg.

Saaty, T. L. (1990a). How to make a decision: the analytic hierarchy process. European Journal of Operational Research, 48(1), 9-26.

Saaty, T. L. (1990b). An exposition of the AHP in reply to the paper "remarks on the analytic hierarchy process". Management Science, 36(3), 259-268.

Sharma, B. P., Singh, M. D., \& Kumar, A. (2012, August). Knowledge sharing barriers: An integrated approach of ISM and AHP. In Proceedings of the international conference on information and knowledge management (ICIKM 2012) (Vol. 45, pp. 227-232).

Shi, H., Peng, S. Z., Liu, Y., \& Zhong, P. (2008). Barriers to the implementation of cleaner production in Chinese SMEs: government, industry and expert stakeholders' perspectives. Journal of cleaner production, 16(7), 842-852.

Sizhen, P., Yan, L., Han, S., \& Ping, Z. (2005). Studies on barriers for promotion of clean technology in SMEs of China. Chinese Journal of Population Resources and Environment, 3(1), 9-17.

Skeat, J., \& Roddam, H. (2010). What are the barriers to EBP in speech and language therapy?. Embedding Evidence-Based Practice in Speech and Language Therapy: International Examples, 16.

Wang, M., \& Liao, Y. (2011). AHP analysis on barrier influent factors of management communication. Science and Technology Management Research, 7, 059. 
Wijayatunga, P. D., Siriwardena, K., Fernando, W. J. L. S., Shrestha, R. M., \& Attalage, R. A. (2006). Strategies to overcome barriers for cleaner generation technologies in small developing power systems: Sri Lanka case study. Energy Conversion and Management, 47(9), 1179-1191.

Wu, Y., \& Li, N. (2004). Analysis of Influencing Factors of Technical Barriers on Information Product Exports Based on the Fuzzy AHP. Journal of Systems Science \& Information, 2(4). 